\title{
Influence of Laterality on Motor Performance and Visual Exploration in Congolese Football Collegians
}

\author{
Tira Juslain Joël1, Tira Alfred1, Mviri Hubert Cesaire1, Massamba Alphonse ${ }^{2 *}$ \\ ${ }^{1}$ Laboratory of Didactic of Physical Education, Higher Institute of Physical and Sports Education, Marien Ngouabi University, \\ Brazzaville, Congo \\ ${ }^{2}$ Laboratory of Sport Biosciences, Higher Institute of Physical and Sports Education, Marien Ngouabi University, \\ Brazzaville, Congo \\ Email: ${ }^{\star m b o y a 53 @ g m a i l . c o m ~}$
}

How to cite this paper: Joël, T. J., Alfred, T., Cesaire, M. H., \& Alphonse, M. (2017). Influence of Laterality on Motor Performance and Visual Exploration in Congolese Football Collegians. Advances in Physical Education, 7, 444-456.

https://doi.org/10.4236/ape.2017.74037

Received: September 4, 2017

Accepted: November 13, 2017

Published: November 16, 2017

Copyright $\odot 2017$ by authors and Scientific Research Publishing Inc. This work is licensed under the Creative Commons Attribution International License (CC BY 4.0).

http://creativecommons.org/licenses/by/4.0/

\begin{abstract}
In order to evaluate the impact of functional laterality on motor performance and visual exploration in football among secondary school students in Congo-Brazzaville, 1734 boys of mean age $13.6 \pm 0.9$ years were recruited. They were subjected to a learning cycle with 9 lessons. Motor tasks were juggling balls, passing, and shooting. Visual exploration consisted of placing the ball on a viewing and unobserved landscape of a playground. Our results suggest that the learning cycle revealed an improvement in perceptual-motor tasks throughout training. Our data allow us to conclude that the strategies proposed are developed in a way that is consistent with the aim pursued.
\end{abstract}

\section{Keywords}

Football Learning, Physical Education, Perceptual-Motor Performance, Pupil, Congo

\section{Introduction}

Physical Education and Sport (EPS) is a teaching discipline which, through the body, participates in the formation of the child's personality. In this sense, it contributes to the development of social, psychomotor and affective cognitive domains. Physical and Sports Activities (APS) are a powerful means of expressing the child's development, particularly in schools. Among them is football.

The numerous studies on the learning of football at school have led to a reflection on the interest and legitimacy of this specialized sports practice and its 
apprenticeship in young children as part of its overall development and more particularly psychomotor (Fitts, 2004).

Nowadays, the standards adopted in football education focus on competences considered as priorities because they are coherent with the new role of teachers, the evolution of the continuous sports discipline and reforms in the training of young people at the school (Keller et al., 1979). These include: introducing learning cycles; differentiating pedagogy and developing teamwork by the teacher and the collective care of students. These are at the heart of pedagogical action through the use of active methods and learning by open problems and problem situations.

Most of the references that are inspired by football try to grasp the movement of the experts by insisting on nine major families subject to the following objectives (Bonnet \& Lestienne, 2003): 1) organize and animate learning situations; 2) manage the progression of learning; 3) design and develop differentiation schemes; 4) involve students in their learning and work; 5) working as a team; 6) participate in the management of the school; 7) inform and involve parents; 8) use new technologies; 9) manage its own continuing education.

This inventory is neither final nor exhaustive. Moreover, no reference system can guarantee a consensual, complete and stable representation of the competencies that it implements. However, these chapters have no other ambition than to help to form increasingly precise representations of the competences in question (Henderson, 2003). This is the condition for a debate and a gradual rapprochement of points of view.

The frame of reference used in this study associates with each main competence a more specific competences, which are in a way its main components. For example, "managing the progression of learning" in college football mobilizes five more specific skills: 1) designing and managing problem situations adjusted to the level and the possibilities of the students; 2) acquiring a longitudinal vision of the objectives of education; 3 ) linking to the theories that underlie learning activities; 4) observing and evaluating students in learning situations, using a formative approach; and 5) preparing periodic assessments of competencies and making progress decisions.

Each could be decomposed in turn, but we will stay at this level, lest "the trees hide the forest". A finer decomposition would be meaningful only for those who generally share the general orientations and conceptions of learning and the educational action that underlie the first two levels and intend to put the reference system at the service of a joint project.

However, knowledge related to metacognition is mobilized by skills dealt with in different chapters. Examples include: working from mistakes and obstacles to learning football; design and manage problem situations adjusted to the levels and possibilities of students in the discipline in relation to the development of the body pattern of the growing child.

In the context of Congo (Brazzaville), the teaching of football in Physical Education (PE) raises problems, in particularly concerning the involvement of 
the laterality of the body regimen in the situations of visual exploration (peripheral and central) in the school disciplined. Indeed, the majority of teachers of PE don't take into account laterality in the strategies implemented.

Thus, the following question may arise: does the learning of pupils in the teaching of football in PE at the secondary school relate to the laterality of the learner in the development of motor skills and visual exploration (ball and game) during the teaching/learning of football?

From our observations on the ground and from this questioning, we can formulate the following hypothesis: the management of the laterality of the child helps to maximize the motor performance in football in the peripheral and central vision, in decreasing the number of observed areas.

The aim of this work is to analyze the impact of laterality on motor behavior and the development of perception during a football learning cycle. The specific objectives are to assess the influence of laterality on the accuracy of shots, passes, driving and ball control, to examine the interrelation between the score established in the different gestures.

\section{Materials and Methods}

\subsection{Type of Study and Tallies Space-Time}

The longitudinal type study was carried out from 13 November 2014 to 21 May 2016 in 58 schools (11 public and 47 private) located in 10 departments of Congo-Brazzaville.

Figure 1 summarizes the school selection process.

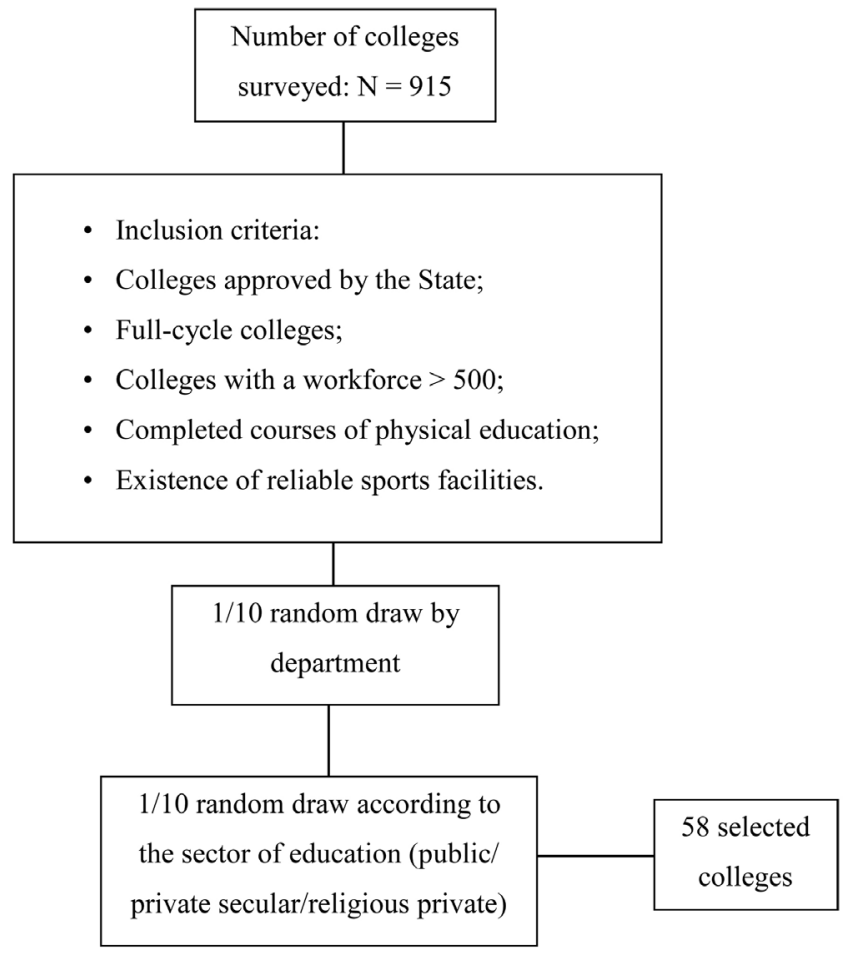

Figure 1. Summarizes the school selection process. 
For private schools, tuition fees were another criterion for inclusion: indeed, adequate sports facilities were rated in high-cost schools, as noted by Mabiala-Babela et al. (2005). The criterion of selection of the department was based on the density of the population in relation to that of the country and the quality of the school sports infrastructures recovered. In addition, the 5th grade of general secondary education was selected because of the first use of football as a teaching medium for PE, according to official texts.

\subsection{Sampling}

In total, the population of college students was 318,725 . The sample size was calculated from the formula (Huguier \& Boëlle, 2013):

$$
n=\frac{N b^{2} \sigma^{2}}{(N-1) e^{2}+b^{2} \sigma^{2}}
$$

where $N$ is the total population of students between 12 and 16 years, $e$ is the estimation error, $b$ is the probability threshold at $95 \%$ and $\sigma$ is the standard deviation. In our case, we have: $N=318,725 ; e=2.43 ; b=1.96 ; \sigma=37.69$.

Replacing these values in Equation (1), we obtain for sample size: $n=920$. The subjects selected in the study were male pupils aged 12 - 15 years (mean age: $13.6 \pm$ 0.9 years), subjected to an exploratory test of functional laterality (ocular, manual and pedestrian) according to Galifret-Granjon lateral dominance battery (Dailly \& Moscato, 1984). In this study, the written consent of the parents was a prerequisite for being retained in the experiment. All subjects were regular at PE courses and practiced football in the neighborhoods. The study excluded: children playing football in sports schools or structured teams; having a state of health which did not permit the practice of sport on presentation of a medical certificate of physical fitness; not having a written agreement from the parents to participate in the study. The non-inclusion of girls in this study was due to their lack of motivation in PE and the probable presence of unreported pregnancies.

Physical fitness tests were carried out within the hospital of the department. These included anthropometric (height, weight, percent of fat), hemodynamic (heart rate; pulse pressure), respiratory (FEV1, CV, DEP) and biochemical (blood glucose, thick drop) data.

Table 1 relates the anthropometric characteristics of subjects and sex. In total, the final sampling was 1734 boys.

Table 1. Anthropometric data of subjects.

\begin{tabular}{cccc}
\hline & Mean \pm DS & Range & \\
\hline Height $(\mathrm{m})$ & $1.59 \pm 0.45$ & 1.38 & 1.65 \\
Weight $(\mathrm{kg})$ & $47.2 \pm 1.3$ & 35.2 & 58.3 \\
BMI $\left(\mathrm{kg} / \mathrm{m}^{2}\right)$ & $18.7 \pm 0.6$ & 12.4 & 20.1 \\
H $(\mathrm{cm})$ & $0.96 \pm 0.2$ & 0.59 & 1.18 \\
\hline
\end{tabular}

Abbreviations: DS, Deviation Standard; BMI, body mass index; H, height of gravity mass center. 
This study, which received the approval of the Ethics Committee of the General Delegation of Scientific and Technical Research, Medical Committee, met the criteria of Helsinki II.

\subsection{Experimental Procedure}

The football teaching program consisted of 18 lessons, distributed in 9 lessons per cycle. The tasks assigned to the students were juggling (coordinating the movement of the legs and head while keeping the ball in air); conducting the ball (mastering the contact used to conduct the ball during a technical course timed with or without shot); ball strikes (shooting accurately in the indicated areas); the passes (accurately transmit the ball towards the partner). During the course of these tasks, the students had to be able to develop individual techniques such as: juggling, dribbling; dribbling and shooting at the goal, driving the ball, making the pass, running fast. The achievement of these different objectives was assessed and noted by the teacher (experimenter) before and after the learning cycle using the Likert descriptive-numeric scale (from 0 to 5 points). For evaluate visual exploration during a motor task, a NAC EYE MARK RECORDER photo-oculograph has been used. This apparatus makes it possible to obtain permanently on a tape recorder the image of the ground situated in front of a subject. This technique is based on the properties of corneal reflection (Dinard et al., 2009). The field of experimentation was based on a circle $20 \mathrm{~m}$ in diameter, divided into 12 angular sectors (Figure 2).

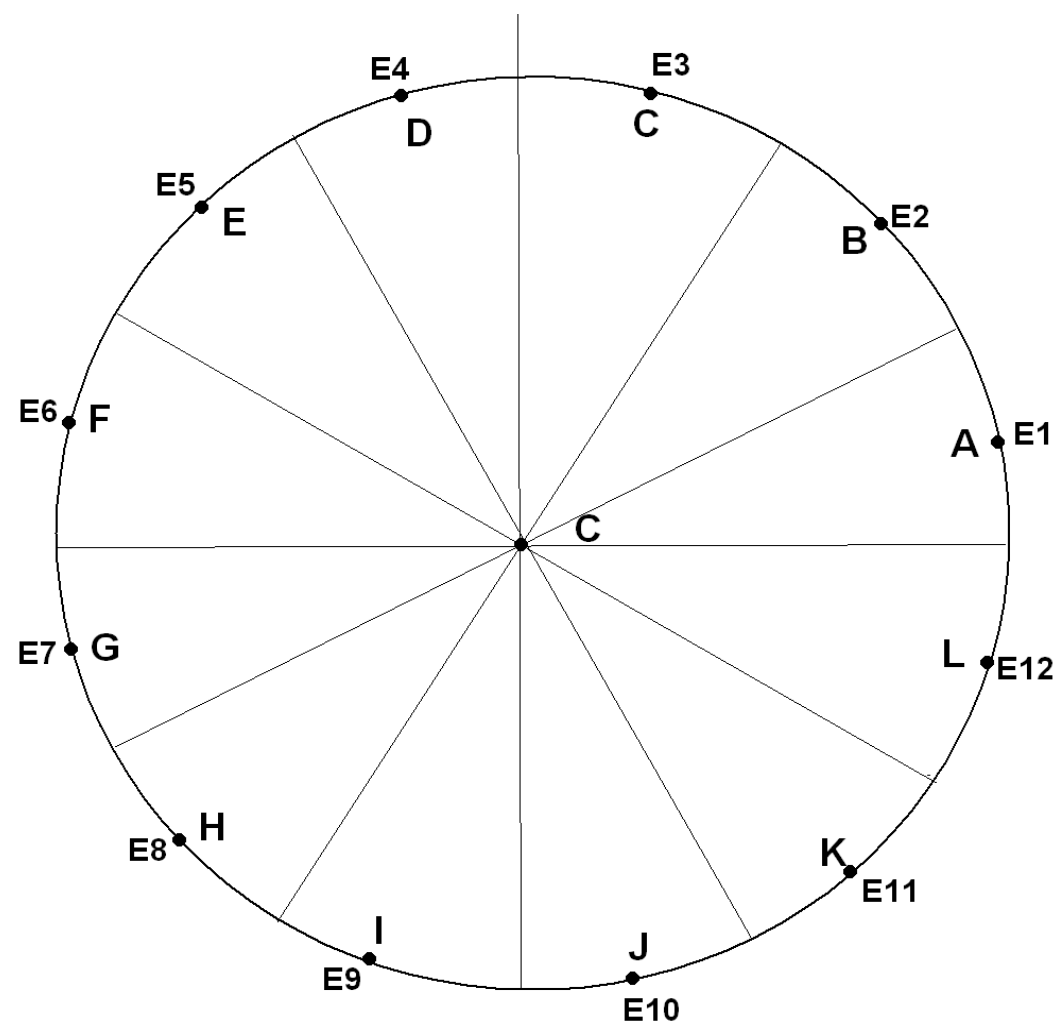

Figure 2. Disposition of the evaluated subjects and evaluators. 
The subject evaluated was at the center $\mathrm{C}$ of the circle (Figure 2). In total, 12 evaluators (E) were placed in the middle of each area of the circle $(A, B, C, \ldots, K$, L). Each of them possessed a plate bearing a letter A, B, C, D, E, F, G, H, I, J, K, L. The field of vision corresponded to E1; E2; E3; E4; E5; E6, invisible areas at E7; E8; E9; E10; E11; E12.

At the audible signal, a visible field evaluator, in a random order, lifted his plate, and the assessed ran towards him to hit the ball in front. This should be directed to the evaluator located in the opposite axis, in the invisible field.

For each evaluator of the visible field, the subject had 5 tests with a total of 20 tests for the 6 evaluators. The performance (success/failure) selected for a given area was the average of the scores established for the 5 trials. For that, a ball struck in the axis counted 5 points; for a ball passing at $1 \mathrm{~m}$, the score was 3 points and beyond $1 \mathrm{~m}, 1$ point. This scale was based on the study by DitDinard et al. (2009). Similarly, this variable was evaluated according to whether the subject was shooting in the area to the right (E7 to E9), or to the left (E10 to E12).

\subsection{Operational Definitions}

Being lateralized is a characteristic of humans that preferentially use one hand: it is to be left-handed or right-handed. Being skilled with both hands is ambidexterity. The human brain (and to a lesser degree that of other vertebrates) is anatomically nearly symmetrical, so that one of the two hemispheres is symmetrical to the other hemisphere. However, there is a significant functional asymmetry: each hemisphere takes care of certain tasks that are more or less specific to it; we are talking about hemispheric specialization. In the case of homogeneous right-handed subjects (right hand, foot, eye and ear), the left hemisphere has an essential role for precise, intentional, well-categorized gestures; it is said to be the "digital" hemisphere. The other hemisphere, which is more specialized in managing the body to serve the intentions targeted by the digital hemisphere, manages the more global, more visual data; it is called an "analog" hemisphere.

The right-hand side was considered a right-hand laterality.

The awkwardness was associated with a left laterality (manual, pedestrian, visual).

Laterality was designated ambivalent in the case of pedestrian laterality, but not manually and visually.

The same definition was adopted in the case of lateral visual, but not pedestrian and manual; or manual laterality, but not visual and pedestrian.

\subsection{Study Variables}

It was limited to the score achieved in the "juggling" task according to the laterality, the performance performed by the learner during the timed course associated with the execution of a shot according to the preferred foot and the success rates of the shots. These performances were evaluated before and after the learning cycle. Finally, the relationship between shooting mark and dominant 
laterality was examined during the juggling tasks.

\subsection{Statistical Analysis}

The scores obtained were presented as mean and standard deviation. For this purpose, descriptive and differential statistical techniques have been used. For descriptive statistics, it was summarized in the calculation of enrollments and percentages, as well as the arithmetic mean and the standard deviation. Numerous inferential statistical tests were used. First, the $t$ Student test was used to compare two means of pre- and post-cycle scores between left-handers and right-handers for the same lateral dominance.

The variance analysis (ANOVA) was used to assess the perceived variation in the success of shots based on lateral dominance. When significance was obtained for ANOVA, the most significant level was determined from the Dunn-Bonferroni post-hoc test. On the other hand, a table summarizes before and after the cycle for each sector explored during the shooting session the average value of the duration of the look of these sectors for the students whose right foot is the one of predilection. For this, an analysis between duration and number of shutdowns on the sectors was carried out by a rank comparison using the $\rho$ Spearman test. The significance limit of this test is 0.60 . For all other tests, the significance threshold was set at $5 \%$.

\section{Results}

The performances according to the preferred foot during the juggling test are reported in Table 2.

The performances achieved according to the preferred foot had improved after the football cycle. However, the best scores were significantly found among students playing with the favorable right foot $(3.0 \pm 0.2$ versus $2.2 \pm 0.3)$ as opposed to the unfavorable right foot $(2.3 \pm 0.1$ versus $1.7 \pm 0.3)$.

As for the scores obtained during the pre and post test on the left foot (Table 3 ), it appears that there was no significant difference in the performances performed according to the striking foot during the pre-test. However, the highest values were found in few subjects, both for the FLF and for the ULF.

There was no significant difference in the performance of the striking foot.

Table 2. Means, standard deviations of results according to the predilection of the right foot in the pre and post test.

\begin{tabular}{ccccccccc}
\hline & \multicolumn{4}{c}{ FRF } & \multicolumn{4}{c}{ URF } \\
\cline { 2 - 8 } & $\mathbf{n}$ & Before & $\mathbf{n}$ & After & $\mathbf{n}$ & Before & $\mathbf{n}$ & After \\
\hline Good (/5) & 127 & $3.2 \pm 0.2$ & 102 & $4.5 \pm 0.3^{*}$ & 42 & $2.6 \pm 0.3$ & 68 & $3.2 \pm 0.1^{*}$ \\
Average (/3) & 381 & $2.7 \pm 0.5$ & 585 & $3.6 \pm 0.3^{*}$ & 307 & $2.2 \pm 0.2$ & 416 & $2.9 \pm 0.2^{\star}$ \\
Low (/1) & 359 & $0.7 \pm 0.1$ & 180 & $0.9 \pm 0.1$ & 518 & $0.4 \pm 0.3$ & 203 & $0.7 \pm 0.1$ \\
Mean \pm DS & 867 & $2.2 \pm 0.3$ & 867 & $3.0 \pm 0.2^{*}$ & 867 & $1.7 \pm 0.3$ & 867 & $2.3 \pm 0.1^{\star}$ \\
\hline
\end{tabular}

Abbreviations: FRF, favorable right foot; URF, unfavorable right foot; ${ }^{\star} p<0.05$. 
Table 3. Averages, standard deviations of results according to the predilection of the left foot in the pre and post test.

\begin{tabular}{|c|c|c|c|c|c|c|c|c|}
\hline & \multicolumn{4}{|c|}{ FLF } & \multicolumn{4}{|c|}{ ULF } \\
\hline & $\mathbf{n}$ & Before & $\mathbf{n}$ & After & $\mathbf{n}$ & Before & $\mathbf{n}$ & After \\
\hline Good (/5) & 72 & $4.0 \pm 0.1$ & 116 & $4.6 \pm 0.2^{*}$ & 38 & $3.4 \pm 0.2$ & 45 & $3.7 \pm 0.1$ \\
\hline Average (/3) & 342 & $2.6 \pm 0.2$ & 585 & $2.8 \pm 0.1$ & 317 & $2.2 \pm 0.1$ & 370 & $2.5 \pm 0.2$ \\
\hline Low $(/ 1)$ & 453 & $0.6 \pm 0.3$ & 180 & $0.8 \pm 0.1$ & 512 & $0.4 \pm 0.1$ & 452 & $0.6 \pm 0.3$ \\
\hline Mean \pm DS & 867 & $2.4 \pm 0.2$ & 867 & $2.7 \pm 0.2$ & 867 & $2.0 \pm 0.1$ & 867 & $2.8 \pm 0.1$ \\
\hline
\end{tabular}

Abbreviations: FLF, favorable right foot; ULF, unfavorable right foot; ${ }^{*} p<0.05$.

Nevertheless, higher values were noted in fewer subjects, both for FLF and ULF. The finding was similar to the pre-test. Moreover, whatever the striking foot, the best scores were found only in groups with low numbers, the difference not being significant $(p<0.05)$ between the two tests.

The time taken during the timed course combined with a shooting during the pre and post test (Table 3 ) indicated that the low performances predominated in terms of numbers regardless of the right foot. However, during the post-test, an improvement in numbers was noted at the highest running times. As for the left foot, it was found that more than half of the subjects had performed poorly, the longest running times being recorded in URF subjects.

The correlation values $r$ between the timed run time and the success/failure numbers of the firings before and after the cycle are shown in Table 4.

For the success rate before and after the cycle, the percentages found are shown in Table 5.

This table shows that the only significant differences between the percentage before and after the cycle were found at the URF and ULF levels. Nevertheless, the highest percentages of success in shooting were noted after the cycle.

The times of the strike in the various zones are shown in Table 6.

It appears that students visually explored areas of fire after the learning cycle. This variation was characterized by an exploration that moved from the dominant eye towards the center of the target area. In addition, the average lengths of consultation on the different sectors of fire were increasingly different when one went from E7 to E12 (invisible field). On the other hand, from E1 to E6, the areas most viewed were those facing and oblique, and the likelihood of success of the passes was relatively comparable for each sector. Then gradually, some areas were more explored in the visible field.

\section{Discussion}

The aim of this study was to analyze the impact of functional laterality according to pedestrian dominance on motor performance related to ball juggling, shooting, passing in Congolese students during a learning cycle of football in a school context. The main results obtained from the present work are as follows. Improvement was observed in juggling tasks before and after the learning cycle, 
Table 4. Coefficients $r$ of correlation during pre and post-test.

\begin{tabular}{ccccc}
\hline & \multicolumn{2}{c}{ SS } & \multicolumn{2}{c}{ US } \\
\cline { 2 - 5 } & Before & After & Before & After \\
\hline Good & $0.52^{*}$ & $0.76^{* *}$ & 0.27 & 0.40 \\
Average & $0.46^{*}$ & $0.48^{*}$ & 0.14 & 0.35 \\
Low & 0.28 & 0.37 & 0.12 & 0.31 \\
\hline
\end{tabular}

Abbreviations: SS, successful shot; US, unsuccessful; ${ }^{\star} p<0.05 ;{ }^{* *} p<0.01$.

Table 5. Rate (\%) of success in shooting before and after the cycle according to the preferred foot.

\begin{tabular}{cccc}
\hline & & Before & After \\
\hline FRF & Good & 61 & 71 \\
& Average & 46 & 56 \\
& Low & 30 & 44 \\
& & & \\
& Good & 48 & 53 \\
& Average & 35 & 46 \\
& Low & 27 & 37 \\
& Good & & 51.7 \\
& Average & 47.7 & 57.0 \\
& Low & 52.3 & 39.0 \\
& & 36.7 & 45.3 \\
& Good & & 52.7 \\
& Average & 39.3 & 2.0 \\
\hline
\end{tabular}

Abbreviations: FRF, favorable right foot; URF, unfavorable right foot; FLF, favorable right foot; ULF, unfavorable right foot.

Table 6. Average duration of shooting in the different sectors before and after the cycle and ranking among the subjects with favorable right foot (FRF).

\begin{tabular}{ccccc}
\hline & \multicolumn{2}{c}{ Before } & \multicolumn{2}{c}{ After } \\
\cline { 2 - 5 } & $\mathbf{t}(\mathbf{s})$ & Rank & $\mathbf{t}(\mathbf{s})$ & Rank \\
\hline E1 & 75 & 7 & 68 & 11 \\
E2 & 107 & 8 & 49 & 8 \\
E3 & 65 & 9 & 77 & 3 \\
E4 & 57 & 10 & 66 & 12 \\
E5 & 70 & 2 & 64 & 1 \\
E6 & 44 & 11 & 63 & 6 \\
E7 & 63 & 5 & 42 & 9 \\
E8 & 61 & 6 & 62 & 5 \\
E9 & 60 & 12 & 52 & 4 \\
E10 & 68 & 4 & 44 & 10 \\
E11 & 69 & 1 & 60 & 2 \\
E12 & 72 & 3 & 51 & 7 \\
\hline
\end{tabular}


with the percentage difference between the right foot $(+36.4 \%)$ and the right foot unfavorable $(+32.3 \%)$ being insignificant. Nevertheless, the best performances after the cycle were found in the students who performed the task with the FRF (4.5 points against 3.2 points). The finding was similar for the left foot: 4.6 points for the FLF versus 3.7 points for the URF. Our observations are similar to those of several authors. In all these researchers on psychomotricity, the claim of a deliberate and conscious control of motor tasks according to the dominant laterality remains central. For Boulch (1982), there is no question of educating a typical attitude, but it is a question of drawing the student's attention to the means of controlling and valuing the motor task accomplished in relation to the lateral pedal function dominant.

In the same sense, Gréhaigne, Billard, Guillon and Roche (1989), by introducing the concepts of rules and principles of action into functional laterality in physical education, states that these rules of action are "clearly related to variations in potentials evoked somatic" in the processing of information related to the performance of motor tasks. Indeed, since 1965, "brain potentials associated with events" have been the subject of numerous studies (Desmedt, 1984; Donchin, 1982; Karrer et al., 1984; Mc Callum et al., 1986). Hebrard and Pineau (1994) put these rules and principles at the center of the contents taught in physical education in disciplines where functional laterality plays a fundamental role (the case of football): "we do not teach facts, fragments of skills, automatisms, we teach structures, relations, principles, rules, ...”. We cannot better express the primacy of the dominant laterality on the precision of the realized gesture. Gréhaigne and Guillon (1991) refer explicitly to Piaget's work, in particular to the analyzes developed in "Réussir et comprendre" (1974) and "La prise de conscience" (1974).

The theory of step-by-step training, proposed by Galpérine (2000) in school football, also emphasizes the role of functional laterality in the development of the student's motor skills, emphasizing the importance of the knowledge available to the physical education teacher to carry out a given motor task in the pupil. We can cite in particular Piard (2007) which proposes a pedagogy of the models of tactical decision postulating "that the intervention of the laterality is decisive in the orientation and the driving control of the actions on the teaching of the football". The author insists on the need to present to young learners in the school environment rational guidelines, containing all the identifiers of identification of the functional laterality, "for a coherent construction of the football activity". At a time when Congolese teachers of physical education do not take into account the laterality of the child during the learning of the various sports activities selected, our results suggest a revision of the strategies proposed for football young pupils.

Moreover, another objective of our study was to check whether the proposed learning cycle could modify the functional exploration of the playing field through the precision of the shots, passes, etc. A classification of the sectors of 
the field of vision has been proposed. As shown in Figure 1, the mostly watched sector is that which corresponds to E6. However, after the cycle different sectors were also explored in the invisible area. This supports our hypothesis. At the beginning of the apprenticeship, the young student favors the zone of his direct field of vision. It thus appears that our students did not attach the same importance to the informational zones of the invisible field. However, if we consider that the area of fire is the most informal area of the field, as it is the area that is favored by the young learner, the visual behavior and the duration the execution of the shots.

Indeed, this is justified at the end of the cycle by the fact that the visual strategy is modified in the sense of optimization, at the same time that the subject becomes more profitable in terms of the success and precision of the shots, juggling, etc. In terms of validity internal to our experience, our observations allow us to say that the subjects respected the instructions that were assigned to them. They are important because they allow us to argue that the implementation of the learning strategy has facilitated motor readiness by facilitating the initiation and/or implementation of an appropriate motor response (Singer et al., 1996). This hypothesis corroborates the neuropsychological data which underline the similarities existing between the cerebral activity involved in the preparation of the action and its execution (Decety et al., 1997; Grèzes \& Decety, 2001). All of our findings, neuropsychological data and previous experimental work (Bekkering \& Neggers, 2002; Fischer \& Hoellen, 2004; Hannus et al., 2005) suggest that increased visual attention after our football learning cycle can be considered as a selection mechanism for the selected motor tasks (Deubel \& Schneider, 1996; Rizzolatti \& Craighero, 1998). More specifically, the effect on visual exploration of the congruence between action and fixation of the firing range, we can say that the processing of visual information is not more complex with or without congruence in the extent to which the quantification of durations differs significantly before and after the cycle (Table 6), from the visual field visible to the invisible (Goldberg \& Kotval, 1999; Henderson, 2003). Thus, our observations allow us to put forward a strategy of visual exploration which varies throughout the learning cycle. This leads to the conclusion that Bekkering and Neggers (2002) or Hannus et al. (2005) have a significant effect of the learning cycle adopted on the development of visual exploration.

However, the weakness of our sample does not allow us to extrapolate our results to the entire Congo school population. This is a limit of the study. Furthermore, carrying out medical examinations by different doctors, whether specialists or not in pediatrics, can contribute to bias in the collection of data. Nevertheless, this study is the first to be carried out in our country, hence its strength.

\section{Conclusion}

Our results support the impact of pedestrian laterality on motor performance in 
a teaching/learning cycle of football among the young pupils in Congo-Brazzaville. Moreover, there is a correlation between acquired competence and visual behavior. It would then be interesting to consider the construction of a film, showing this procedure, and explain to teachers its importance. Finally, our methodology allows us to consider other approaches to try to supplement our knowledge about other motor tasks.

\section{References}

Bekkering, H., \& Neggers, S. (2002). Visual Search Is Modulated by Action Intentions. Psychological Science, 13, 370-374. https://doi.org/10.1111/j.0956-7976.2002.00466.x

Bonnet, C, \& Lestienne, F. (2003). Perceiving and Producing Movement. Paris: Armand Colin.

Dailly, R., \& Moscato, M. (1984). Lateralization and Laterality in Children. Bruxelles: Mardaga.

Decety, J. et al. (1997). Brain Activity during Observation of Action: Influence of Action Content and Subject's Strategy. Brain, 120, 1763-1777. https://doi.org/10.1093/brain/120.10.1763

Desmedt, J. E. (1984). The Non-Cephalic Reference Makes It Possible to Avoid Errors in the Interpretation of the Somesthetic Evoked Potentials in Humans. ElectroEncephalography and Clinical Neuro Physiology, 13, 349-366.

Deubel, H., \& Schneider, W. X. (1996). Saccade Target Selection and Object Recognition: Evidence for a Common Attentional Mechanism. Vision Research, 36, 1827-1837.

Dit Dinard, F. M. et al. (2009). Visual Exploration Strategies: Effect of the Intention of Action on the Observation of Images of Usual Objects. L'Année psychologique, 109, 383-405. https://doi.org/10.4074/S0003503309003029

Donchin, E. (1982). Cognitive Psychophysiology. Hillsdale, NJ: Erlbaum.

Fischer, M. H., \& Hoellen, N. (2004). Space-and Object-Based Attention Depend on Motor Intention. The Journal of General Psychology, 131, 365-377.

Fitts, P. M. (2004). Perceptual-Motor Skills Learning. In A. W. Melton (Ed.), Categories of Human Learning (pp. 243-285). New York, NY: Academic Press.

Galpérine, P. I. (2000). Essay on the Step-by-Step Training of Actions and Concepts. In N. F. Talyzina (Ed.), From Programmed Instruction to Knowledge Programming (pp. 167-183). Presses Universitaires de Lille.

Goldberg, J. H., \& Kotval, X. P. (1999). Computer Interface Evaluation using Eye Movements: Methods and Constructs. International Journal of Industrial Ergonomics, 24, 613-645.

Gréhaigne, J. F. et al. (1989). Towards a Different Conception of the Teaching of Collective Sports. In G. Bui-Xuan (Ed.), Methodology and Didactics of EPS (pp. 201-216). Clermont-Ferrand: Editions AFRAPS.

Gréhaigne, J. F., \& Gillon, R. (1991). Good Use of the Rules of Action. Echanges et Controverses, 4, 43-66.

Grèzes, J., \& Decety, J. (2001). Functional Anatomy of Execution, Mental Simulation, Observation and Verbal Generation of Actions: A Meta-Analysis. Human Brain Mapping, 12, 1-19.

https://doi.org/10.1002/1097-0193(200101)12:1<1::AID-HBM10>3.0.CO;2-V

Hannus, A. et al. (2005). Selection-for-Action in Visual Search. Acta Psychological, 118, 
171-191.

Hebrard, A., \& Pineau, C. (1994). Physical Education and Sports Program Master Plan. Revue EPS, 247, 49-51.

Henderson, J. M. (2003). Human Gaze Control during Real-World Scene Perception. Trends in Cognitive Sciences, 7, 498-504.

Huguier, B., \& Boëlle, J. P. (2013). Biostatistics in Everyday Life. Paris: Masson.

Karrer, R. et al. (1984). Brain and Information: Event-Related Potentials. Annals of the New York Academy of Sciences, 425, 768.

Keller, D. et al. (1979). Analysis of Preparatory Adjustments Specific to the Performance of a Sporting Gesture. Education Physique et Sportive, 155, 6-9.

Le Bouch, J. (1982). Towards a Science of Human Movement-Introduction to Psychokinetics. Paris: ESF Editions.

MabialaBabela, J. R. et al. (2005). Adolescent Alcohol Use in Brazzaville-Congo. Cahiers Santé, 15, 153-160.

Mc Callum, W. C. et al. (1986). Cerebral Psychophysiology: Studies in Event-Related Potentials. Electroencephalography and Clinical Neurophysiology, 38, 566.

Piaget, J. (1974). A wareness. Paris: Presses Universitaires de France.

Piaget, J. (1974). Success and Understanding. Paris: Presses Universitaires de France.

Piard, C. (2007). Football and Programmed Instruction. Paris: Vigot.

Rizzolatti, G., \& Craighero, L. (1998). Spatial Attention: Mechanisms and Theories. In M. Sabourin, F. Craick, \& M. Robert (Eds.), Advances in Psychological Science: Biological and Cognitive Aspects (Vol. 2, pp. 171-198). Montreal: Psychology Press.

Singer, R. N. et al. (1996). Visual Search, Anticipation and Reactive Comparisons between Highly Skilled and Beginning Tennis Players. Journal of Applied Sport Psychology, 8, 9-26. https://doi.org/10.1080/10413209608406305 